\title{
Consumer engagement in online brand communities: the moderating role of personal values
}

Article

Accepted Version

Marbach, J., Lages, C., Nunan, D. and Ekinci, Y. (2019) Consumer engagement in online brand communities: the moderating role of personal values. European Journal of Marketing, 53 (9). pp. 1671-1700. ISSN 0309-0566 doi: https://doi.org/10.1108/ejm-10-2017-0721 Available at https://centaur.reading.ac.uk/81123/

It is advisable to refer to the publisher's version if you intend to cite from the work. See Guidance on citing.

To link to this article DOI: http://dx.doi.org/10.1108/ejm-10-2017-0721

Publisher: Emerald

All outputs in CentAUR are protected by Intellectual Property Rights law, including copyright law. Copyright and IPR is retained by the creators or other copyright holders. Terms and conditions for use of this material are defined in the End User Agreement.

www.reading.ac.uk/centaur 
Central Archive at the University of Reading

Reading's research outputs online 
Consumer Engagement in Online Brand Communities: The Moderating Role of Personal Values

(Accepted in November 2018 in the European Journal of Marketing)

Julia Marbach*, Independent Researcher, Germany

Cristiana R. Lages, Henley Business School, United Kingdom

E-mail: c.r.lages@henley.ac.uk

Daniel Nunan, Faculty of Business and Law, United Kingdom

E-mail: daniel.nunan@port.ac.uk

Yuksel Ekinci, Faculty of Business and Law, United Kingdom

yuksel.ekinci@port.ac.uk

*Corresponding author:

Julia Marbach

jmarbach@live.de 


\begin{abstract}
Purpose

Despite growing recognition of the importance of consumer engagement with new technologies, a gap remains in terms of understanding the antecedents, consequences and moderators of online consumer engagement (OCE). This paper aims to address this gap by exploring the relationship between personality traits, OCE, perceived value and the moderating role of personal values.
\end{abstract}

\title{
Design/Methodology/Approach
}

A theoretical framework anchored in the extant OCE literature is tested through a study of 559 users of two distinct firm-hosted online brand communities (FHOBCs).

\section{Findings}

Findings suggest that three personality traits - extraversion, openness to experiences and altruism - are positively correlated with OCE. OCE is related to two types of perceived value, namely social value and aesthetic value. The personal values of conservation and selfenhancement moderate the relationships between the three identified personality traits and OCE.

\section{Research limitations/implications}

Future research into OCE should consider the application of this study's conceptual framework across different cultures to account for the fast changing nature of online communities.

\section{Practical implications}

Understanding how personality traits drive OCE and what value consumers receive from engagement in online communities can help managers to better segment and evaluate consumers. Engagement and levels of activity within these online communities can be improved accordingly.

\section{Originality/Value}

This study's contribution to the OCE literature is threefold. Firstly, the study provides new insights regarding personality traits as antecedents of consumer engagement with FHOBCs. 
Secondly, the study reveals the first insights into the role of personal values in the relationship between personality traits and OCE. Specifically, conservation and self-enhancement emerged as moderators of the relationship between three personality traits (extraversion, openness to experiences, altruism) and OCE. Thirdly, the study yields support for perceived value types (social value and aesthetic value) that emerge as consequences of consumer engagement in FHOBCs.

Keywords: Online consumer engagement; personality traits; personal values; perceived value; firm-hosted online brand communities 


\section{Introduction}

The way that consumers engage with brands is being increasingly influenced by new forms of technology. As a result, understanding how to best engage consumers through these technologies has become a key challenge for managers. While consumer engagement plays a key role in developing memorable consumer experiences (Kumar et al., 2010), the growth in always-connected social platforms gives consumers greater power to control these experiences. Although the digital environment provides companies with unprecedented opportunities to engage with consumers, it also empowers consumers to decide where, and when, to engage. Developing a better understanding of how consumers engage online is therefore crucial to establishing stronger emotional bonds with consumers (Hollebeek, 2013; Rose et al., 2012; Vivek et al., 2012). The significance of this topic is reflected in the growth of scholarly interest in the concept of online consumer engagement (OCE) in recent years (e.g. Brodie et al., 2011; Brodie et al., 2013; Hollebeek and Chen, 2014).

This study addresses a gap in OCE research by examining its antecedents and consequences as well as the moderating impact of personal values on these relationships. Specifically, this study focusses on personality traits as antecedents, an area that has been identified as an important gap for research into OCE (Wirtz et al. 2013). Although some antecedents and consequences of consumer engagement have been included in theoretical models (Van Doorn et al., 2010; Verhoef et al., 2010), there is a paucity of empirical research into the role of personality traits as antecedents of consumer engagement. In particular, existing research has focussed on the relationship between personality traits and social media usage in general (Correa et al., 2010; Lee et al., 2014; Marshall et al., 2015; Seidman, 2013) rather than consumer engagement with brands across online channels. While recent studies (e.g. Marbach et al., 2016; Islam et al., 2017a) have begun to investigate the role of personality traits as an antecedent of OCE, these studies are based on Facebook and not on the more general context of firm-hosted online brand communities (FHOBCs). Additionally, the moderating impact of personal values on the relationship between personality traits and OCE has not yet been investigated.

Moreover, the relationship between OCE and consumer value has not been fully examined, despite perceived value being identified as a potential consequence of OCE (Brodie et al., 2013; Hollebeek, 2011; Jaakkola and Alexander, 2014; Kumar et al., 2010; Maslowska et al., 2016; Schau et al., 2009; Sung et al., 2010). While Higgins and Scholer (2009) and Hollebeek (2013) provide support for a possible relationship between OCE and perceived value, Hollebeek (2013) 
calls for further research to examine this relationship. Accordingly, the study aims to make three contributions to existing knowledge. First, this study addresses the calls by previous scholars highlighting that it is worthwhile to investigate what drives online consumer engagement (Hollebeek, 2013; Wirtz et al., 2013; Bolton, 2011). Understanding the drivers of consumer engagement is important because one of the primary objectives of brand management is to develop and implement successful consumer engagement in order to retain as well as grow membership numbers for online brand communities. Hence, understanding what drives consumers to engage in online brand communities and what value they derive from online brand engagement are critical. Although recent studies (Marbach et al. 2016; Islam et al. 2017a) examined the role of personality traits as antecedents of OCE, this study extends Islam et al.'s (2017a) work by investigating new personality traits, namely altruism, as well as the role of consumer-perceived value as a consequence of OCE. Additionally, this study extends Marbach et al.'s work (2016) by investigating the moderating role of personal values in the relationship between personality traits and OCE. This study also investigates personality traits as antecedents and consumer values as consequences of OCE in a large scale quantitative study focussing not only on the social media content but on the broader FHOBC context as well, contrary to Marbach et al. (2016).

Second, the study adds new insights into the relationship between personality traits and OCE by examining the effect of personal values as a moderator of this link. To the best of our knowledge, examination of personal values as a moderator of the relationship between personality traits and OCE is limited (Wirtz et al. 2013; Sung et al. 2010; Hollebeek, 2011). Personal values are deeply rooted concepts that guide consumer behaviour, perceptions, personality traits and culture and that transcend specific situations and actions (Schwartz and Bilsky, 1987). Hence, it is worthwhile to examine personal values as a moderator for gaining a better understanding of the influences of personality traits in OCE (Wirtz et al., 2013; Soares, Farhangmehr and Shoham, 2007). In addition, the study provides a simultaneous examination of the role of personal values, personality traits and consumer values in order to determine their unique contributions to OCE behaviour.

Third, this study examines the validity of the OCE scale of Hollebeek et al., (2014) and Schwartz's (1999) personal value framework in an international online community setting of FHOBCs. This is important because Hollebeek et al., (2014) calls for further research investigating the external validity of the newly developed OCE scale in other cultural contexts. 
In order to examine the moderating role of personal values in the relationship between personality traits and OCE, the present study also employs a short version of Schwartz's personal values measure for the first time in an online FHOBCs setting. Previous studies predominantly used Hofstede's (1984) cultural values scale, but validity of this measure has been consistently questioned (e.g. Chow et al., 1994; Evans and Mavondo, 2002; Evans et al., 2000; Kim and Gray, 2009; McSweeney, 2002; Schwartz, 1999). In line with previous research calls (Ng et al., 2007; Steenkamp 2001), this study examines the external validity of Schwartz's (1999) personal value measure in a new research setting, namely OCE.

This paper is structured as follows. Firstly, we present the literature on OCE, personality traits, personal values and perceived value, leading to our conceptual framework and research hypotheses. Secondly, we present the findings from an empirical study with consumers who participated across two FHOBCs. Thirdly, the results are discussed alongside theoretical and practical implications. Finally, we present a number of promising directions for future research.

\section{Literature review}

\section{Online consumer engagement (OCE)}

Consumer engagement in online brand communities can be referred to as specific and interactive experiences among consumers, or between consumers and the brand. Consumer engagement is a psychological state that is context dependent and characterised by fluctuating intensity levels that occur within dynamic and iterative engagement processes (Brodie et al., 2013). Part of the relationship-marketing domain, consumer engagement can be described as a central concept within marketing. The focus of consumer engagement is on interactive consumer experiences (Vivek et al., 2012), an important development in customer management that goes beyond simple transactions (Verhoef et al., 2010).

Despite a growing body of research on consumer engagement, there is little consensus on how it is determined. While several authors highlight that consumer engagement consists of three dimensions, namely cognitive, behavioural (active) and emotional (affective) (e.g. Algesheimer et al., 2005; Brodie et al., 2013; Vivek, et al., 2012), others support the existence of one or two of these dimensions (e.g. Bejerholm and Eklund, 2007; Huo et al., 2009; Marks, 2000). The unidimensional nature of the concept possesses the merit of simplicity but it does not reflect its rich conceptual scope (Hollebeek, 2011). Research gaps remain in terms of investigation of the antecedents, moderators and consequences of OCE as these have been included in theoretical 
models (Van Doorn et al., 2010; Verhoef et al., 2010) but have not been empirically examined in great detail to date (Hollebeek et al., 2014).

\section{Personality traits}

The personality trait theory suggests that individuals behave in a certain way because of the personality traits they possess (Feist and Feist, 2008). A personality trait can be defined as a cross-situational individual difference, which is temporally stable (Ajzen, 2005), and thus, the trait is expressed in the exact same way in different social settings. Personality traits often reflect what people value, prefer and what motivates them. (Harris and Lee, 2004). Hence, it is generally believed that traits directly influence behaviour (Chen, 2011; Matthews et al., 2009).

The personality trait literature distinguishes between primary and secondary traits (Matthews et al., 2009). The former is narrower than secondary traits, which are broader and include the primary traits (Cattell, 1947; Eysenck, 1991). The taxonomy of secondary traits has long been dominated by the three-factor model (psychoticism, extraversion, neuroticism) (Eysenck, 1991) and the sixteen personality factor model (Cattell, 1947). The Big Five's origins are seen in the work of Fiske (1949), who rated 128 clinical trainees on twenty-two scales of surface behaviour based on Norman's (1963) work, which converted Cattell's (1947) sixteen personality traits into five higher order traits. The factor analysis yielded evidence of the existence of five orthogonal personality factors, namely extraversion, agreeableness, conscientiousness, neuroticism and openness to experiences. Often openness to experiences is called culture, intellect or imagination (Digman and Takemoto-Chock, 1981). Since 1963, the Big Five has become one of the most popular personality instruments in psychology and the best paradigm for personality structure (Costa and McCrae, 1992a; Digman, 1990). However, others argue that restricting personality traits to five factors reduces its predictive ability (Brown et al., 2002). This study takes the latter stance by arguing that the Five Factor Model is limited in explaining peoples' personality (Coelho et al., 2016; Block, 1995; Brown et al., 2002). Hence, we included altruism as an additional personality trait that may drive OCE (Mowen and Sujan, 2005). Altruism has been added as it enables a more comprehensive list of personality traits relevant to a marketing context, in line with previous marketing research that added traits to the Big Five (Brown et al., 2002; Harris et al., 2005; Sousa et al., 2016).

\section{Personal values}

The study adopts the personal value definition introduced by Schwartz (1992), the most commonly used personal value research in the literature (Lindeman and Verkasalo, 2005). 
Personal values are deeply rooted concepts that guide behaviour and they transcend specific situations and actions (Schwartz and Bilsky, 1987). According to Schwartz (1992), people possess ten basic human values: power, achievement, hedonism, stimulation, self-direction, universalism, benevolence, conformity, tradition and security. These personal values are theoretically derived from the general requirements of human life (Schwartz, 1999). The ten personal values form two higher order constructs, namely self-enhancement (i.e. achievement, power) versus self-transcendence (i.e. universalism, benevolence) and openness to change (i.e. self-direction, stimulation) versus conservation (i.e. tradition, conformity, security).

\section{Perceived value}

Perceived value or consumer value can be seen as one of the cornerstones of the marketing discipline (Mustak, 2014). The term "consumer value" is used interchangeably in the marketing literature to portray two perspectives, one where value is derived by the consumer from the supplier and the other perspective where value is derived by the supplier from other companies or producers. The latter is often referred to as customer lifetime value or value for the company (Borle and Singh, 2008; Kumar et al., 2008) whereas the former is referred to as perceived value or value for the consumer (Woodall, 2003). Perceived value represents the demand-side notions of value and has become of more interest to both researchers and practitioners (Woodall, 2003). Perceived value can be seen as the trade-off between the benefits the consumer is realising versus the sacrifices that are required to get these benefits, such as monetary resources, time and stress (cf. Zeithaml, 1988). While some regard perceived value as a unidimensional construct (e.g. Dodds et al., 1991; Monroe, 1979), others see perceived value as multidimensional (Holbrook, 2006; Ruiz et al., 2008). This study adopts Holbrook's (1999, p.5) definition of perceived value as "an interactive, relativistic preference experience" and proposes eight value types, grouped in four categories, namely economic value (efficiency, excellence), social value (status, esteem), hedonic value (play, aesthetics) and altruistic value (ethics, spirituality). The creation of value has become a strategic imperative for companies in order to build and sustain competitive advantage as their customers become more value driven (Wang et al., 2004). Managers need to understand how value is perceived by consumers and where they should focus their attention in order to be able to compete with or even outperform competitors (Woodruff, 1997). 


\section{Personality traits as antecedents of OCE}

Extraversion

Extraverts are regarded as chatty and lively (Mottram and Fleming, 2009), assertive, sociable, outgoing, energetic, optimistic and enthusiastic (Raja and John, 2010) as well as self-confident (McCrae and John, 1992). Introverts tend to be less open minded, find pleasure in solitary activities, like to hide their feelings and are more suspicious (Evans, 1941; Eysenck, 1991). Extraversion is positively linked to social media usage (Correa, et al., 2010; Lee, et al., 2014; Marshall, et al., 2015; Seidman, 2013). A potential reason is that extraverts like to be known by others while introverts view recognition as less important (Ross et al., 2009). Introverted people might engage less online as they are less open to finding new friends who share the same interests (Mottram and Fleming, 2009; Raja and John, 2010). Hence, it is not surprising that extraversion has been associated with greater Facebook use (Gosling and Augustine, 2011). In particular, extraverts are members of more groups on FHOBCs as they prefer to be in social situations rather than being alone (Ross et al., 2009). Therefore, it is proposed that:

\section{H1: Extraversion is positively related to OCE}

Agreeableness

Agreeableness can be seen as a measure of people's friendliness (Costa and McCrae, 1992b) and refers to their general warmth of feelings towards others (Brown et al., 2002). Agreeable individuals are kind, warm, authentic (Costa and McCrae, 1992b; Leary and Allen, 2011), flexible, co-operative, generous and good-natured (Goldberg, 1990). Whereas disagreeable individuals tend to be unfriendly, uncooperative, suspicious, sceptical and prioritise selfinterest (Eysenck, 1991). Usually disagreeable people tend to be indifferent to the well-being of other individuals and thus will be less likely to share their experiences online to help others. On the other hand, agreeable people have characteristics of trust and tender mindedness (Taggar, 2002) that enhance interpersonal skills, necessary for the appreciation of other's contributions. Despite some studies finding that agreeableness is unrelated to social media usage (Correa et al., 2010; Ross et al., 2009), in the broader context individuals who are less agreeable engage less in FHOBCs as they do not appreciate the comments and contributions of peers, or share their experiences to help peers (Schnell and Becker, 2006). The following hypothesis is proposed:

\section{H2: Agreeableness is positively related to $O C E$}




\section{Conscientiousness}

Conscientiousness is the degree of orderliness, organisation and precision (Brown et al., 2002). A higher degree of conscientiousness is associated with a more organised and cautious person (Costa and McCrae, 1992a) with a tendency to meet deadlines and be responsible with obligations (Ross et al., 2009). Interpersonal relationships are also less important for these individuals. Therefore Tsao (2013) argues that conscientious individuals use the internet for the improvement of work skills rather than building relationships with peers in an online community. Engaging in a FHOBC might be seen as a distraction from more important tasks (Butt and Phillips, 2008) which is in line with past studies that investigated time spent on Facebook (Amichai-Hamburger and Ben-Artzi, 2000; Ryan and Xenos, 2011; Wilson et al., 2010). Thus, the following hypothesis is suggested:

\section{H3: Conscientiousness is negatively related to OCE.}

\section{Openness to experiences}

Individuals that are open-minded to experiences constantly seek novelty (McCrae and Costa, 1987), are more changeable and less prone to any prejudices (McCrae and Costa, 1991). They have high curiosity and imagination, are flexible (Madjar, 2008; McCrae and Costa, 1991) and more likely to have a broader range of interests and to pursue those interests through a much wider variety of means (Butt and Phillips, 2008). Additionally, individuals scoring high on openness to experiences seek more information and are more tolerant towards others (McElroy et al., 2007). Hence, the individual will look for opportunities to learn something new (McCrae and Costa, 1991; McElroy et al., 2007), driving online engagement. In line with past research that individuals high on openness to experiences had a greater tendency to be sociable via Facebook (Amichai-Hamburger and Vinitzky, 2010; Correa et al., 2010; Ross et al., 2009), this study hypothesises that:

H4: Openness to experiences is positively related to OCE.

\section{Neuroticism}

Neuroticism refers to the extent to which the emotions of an individual vary (Brown et al., 2002). Individuals high on neuroticism are less able to deal with stress (McCrae and Costa, 1991) and seem easily frustrated and hopeless (McCrae and Costa, 1991). Anxiety is present when the person is not in his/her familiar surroundings and these individuals are more likely to experience depression or irritability (McCrae and Costa, 1991; Suls et al., 1998). 
A new stream of research, namely the 'loneliness theory', has been evolving and supports the argument that neuroticism could be positively related to OCE. This theory suggests that individuals high in neuroticism frequently use the internet to avoid loneliness (e.g. AmichaiHamburger and Ben-Artzi, 2003; Correa et al., 2010; Ryan and Xenos, 2011). These individuals may also look for acceptance and social contact through social networking sites and FHOBCs (Malone et al., 2012). Therefore, this study proposes that:

H5: Neuroticism is positively related to OCE.

\section{Altruism}

Altruism can be regarded as a personality trait (Rushton et al., 1981) and is defined as the general predisposition to selflessly help others (Mowen and Sujan, 2005). Some individuals are simply more generous, more helpful and kinder than others, and several studies demonstrated that these people are perceived as being more altruistic in nature (Dlugokinski and Firestone, 1973; Rutherford and Mussen, 1968). Consumer engagement behaviour can include the willingness to help other consumers, for example in terms of word-of-mouth or through providing feedback (Verleye et al., 2013). In other words, individuals engage online because they enjoy helping others, hence it is proposed that:

H6: Altruism is positively related to OCE. 
The moderating role of personal values on the relationship between personality traits and $O C E$

The idea that personal values moderate the relationship between personality traits and OCE is appealing as personal values guide personality traits and human behaviour (Homer and Kahle, 1988; Roccas et al., 2002; Schwartz and Bilsky, 1987). Recent research argues that it is important to investigate personality characteristics as antecedents of OCE in order to shed more light on this under-researched concept (Hollebeek, 2011; Sung et al., 2010; Wirtz et al., 2013). As previously stated, individuals who possess a specific personality trait are more likely to engage with online marketing activities. Equally, the orientation towards OCE might result from personal values, implying that the strength of the relationship between the two variables (personality traits and OCE) might be dependent on a third variable, namely personal values. There is room for variation in personal values as individuals born in different countries may have different customs, traditions or rules, all of which are embedded in their religious or family values and beliefs, and these may influence their online engagement. That said, even within the same country and cultural context, there can be substantial variation among individuals in the intensity with which they adhere to such social rules and customs. Thus, the self-enhancement dimension might play an important moderating role in the relationship between personality traits and OCE. Those individuals who have self-enhancement values are motivated to pursue social status and prestige. They want to control others and want to be seen as successful and competent according to social norms (Roccas and Schwartz, 2010). Individuals high on selfenhancement are more selfish or self-focussed and by engaging online they can seek attention and at the same time show their achievements. Their life is more focussed on enjoyment and their own personal interests and this is what they like to show to others through engagement with FHOBCs.

Another personal value relevant to the OCE context is conservation. Conservation values express the motivation of an individual to avoid instability and uncertainty. Individuals high on conservation do not stand for independent action and are less ready for new experiences as they adhere to beliefs, customs or traditions that might affect their online engagement (Roccas and Schwartz, 2010). Thus, conservation may weaken the relationship between personality traits and OCE, whereas self-enhancement is proposed to strengthen this relationship as their ambition and drive, resulting from their valuing of success and social power, leads them to engage more online. Their online consumer engagement ensures that they can demonstrate their expertise or share their experiences, keeping others well informed about their own successes or 
social power. Hence, personal values (i.e. self-enhancement and conservation) moderate the relationship between personality traits and OCE behaviour, as expressed in the following hypotheses:

H7a-H7f: Self-enhancement moderates the relationship between extraversion (H7a), agreeableness $(H 7 b)$, conscientiousness $(H 7 c)$, openness to experiences $(H 7 d)$, neuroticism (H7e) and altruism (H7f) and online consumer engagement.

H8a-H8f: Conservation moderates the relationship between extraversion (H8a), agreeableness (H8b), conscientiousness (H8c), openness to experiences (H8d), neuroticism (H8e) and altruism (H8f) and online consumer engagement.

Perceived value (social value and aesthetic value) as a consequence of OCE

While some FHOBCs may have more visitors and be more successful, other communities become abandoned. Hence, engagement might be linked to a value perception by consumers, which ultimately accounts for the difference between successful and failed FHOBCs (Hollebeek, 2013; Seraj, 2012). Value can be seen as a jointly created phenomenon emerging through interaction (Vargo and Lusch, 2008). If an individual is highly engaged he/she will derive intrinsic and extrinsic value from his/her engagement (Vivek et al., 2012).

In this study we focus on two types of value - social value and aesthetic value - as these are especially relevant to OCE. In particular, if an individual shapes the responses of others due to their engagement online, this might be perceived as social value. Social value is of high importance as a community is seen to be collaborative. Thus, no community can be one-sided because customers expect to receive something from engaging online. It is important that individuals engaging in FHOBCs perceive social approval through their engagement. Social approval can be shown by the FHOBC itself, the brand, its employees or users in any form.

Aesthetic value can occur when aesthetic aspects of the FHOBC lead to value creation. For example, through an attractive design or overall appearance of the FHOBC website. An attractive font, easy to use layout or appropriate colours can also contribute to a perceived aesthetic value when engaging in an FHOBC. First impression is linked to aesthetics and this 
should not be underestimated. A well-designed visual design of an FHOBC enhances the content of it and helps to build trust in the community. The main goal of aesthetics should be to enhance customer experience. A well-designed welcome page that invites and encourages users to join the community is crucial to get new customers. Aesthetic value is a result of engaging online if the FHOBC targets their customers in an effective way.

While the relationship between FHOBC practices and consumer value has been theorised (Misra et al., 2008; Porter et al., 2013; Schau, et al., 2009; Seraj, 2012) and supported by propositions relating OCE to value creation (Higgins and Scholer, 2009; Hollebeek, 2013; Jaakkola and Alexander, 2014; Kumar et al., 2010), there is limited empirical evidence of the relationship between OCE and perceived value. Therefore, this study proposes that:

H9: OCE is positively related to social value.

H10: OCE is positively related to aesthetic value.

Figure 1 depicts the conceptual framework summarising the relationships among personality traits, personal values, OCE and perceived value.

[Insert Figure 1 here]

In this conceptual framework, personality traits are regarded as antecedents of OCE whereas the two types of perceived value - social and aesthetic - are regarded as its consequence. Personal value is the moderator in the relationship between personality traits and OCE. H1 to H6 postulate that personality traits (extraversion, agreeableness, conscientiousness, openness to experiences, neuroticism and altruism) are antecedents of OCE. Hypotheses $7 \mathrm{a}-7 \mathrm{f}$ as well as $8 \mathrm{a}-8 \mathrm{f}$ reflect the moderating role of the two personal values - self-enhancement and conservation - in the relationship between personality traits and OCE. H9 and H10 examine the effect of OCE on social value and aesthetic value.

Other potential personality traits are need for activity (Mowen and Sujan, 2005) and need for learning (Mowen, 2000). Need for activity is the enduring motive to do something on a continuous basis (Mowen and Sujan, 2005). Individuals who have a high need for activity have the desire to keep busy and stay active all the time (Licata et al., 2003). Need for learning can 
be defined as a motivating factor, which leads individuals to obtain information and be engaged in a high-level information process (Mowen, 2000). Through this need, a deep understanding of the entire environment can be developed (Mowen and Spears, 1999), as need for activity has the power to inspire individuals to increase their knowledge and thus experience the enjoyment of learning new things (Harris et al., 2005). Many customers may engage with an FHOBC to obtain news from peers or new information (see Harris et al., 2005).

Other potential consumer value types are altruistic value, and economic value in the form of, for instance, efficiency and excellence (Holbrook, 1999). Altruistic value can occur if the purpose of engaging with online media is to help peers, since the individual is motivated by doing something for the sake of others, and is underpinned by a concern about how others will react or how they will be affected by one's actions (Holbrook, 1999). Economic value in the form of Efficiency results from the active use of an FHOBC platform when members may feel that the relevance of the FHOBC content is high or that it is easy to use. Economic value as Excellence involves a reactive appreciation of the experience of engaging online. Excellence value can be generated, for example, through high quality discussion in the community (Holbrook, 1999). Although these additional personality traits and perceived values are relevant variables for future research focussing on OCE and FHOBCs, they were not studied in this investigation.

\section{Methodology}

\section{Research setting}

This study uses data from an online survey carried out in two online communities, namely an FHOBC for customer service support of a major German telecommunications provider and a firm-hosted social media brand community. An FHOBC is a non-geographically bound community formed in cyberspace based on a structured set of social relationships among admirers of a focal brand, a shared consumption practice, a common interest, experience, emotion or passion (Muñiz and O'Guinn, 2001; Wirtz et al., 2013). It is a social entity that not only connects the brand to consumers but also consumers to consumers (Muñiz and O'Guinn, 2001; Wirtz et al., 2013). The community is set up by the company (business to consumer (B2C)) but is sustained by the engagement of consumers (Fournier and Lee, 2009; Muñiz and O'Guinn, 2001; Wiertz and De Ruyter, 2007). Content that is central to consumers' interests is constantly and collectively co-created and consumed and peer-to-peer problem solving is enabled (Harwood and Garry, 2010; McAlexander et al., 2002; Wiertz and De Ruyter, 2007). In line with research indicating that the individual is the most frequent unit of analysis in social 
studies (Corbetta, 2003), this study's unit of analysis is the individual user who is a member of at least one of the selected FHOBCs.

The FHOBC for customer-service support of a German telecommunications provider is a wellestablished community focussing on customer service support. The community is known for engaged members that are heavily involved in creating content and helping others in relation to product specific questions. Thus, the engagement within the community is not only based on a brand manager-consumer/user basis, but also on a consumer-consumer basis, as individuals with the same interests connect in the community. The chosen company uses FHOBCs not only as a marketing and customer support medium, but also as part of a brand management strategy. In establishing an FHOBC, a brand can look to grow and evolve with the expectations and perceived-value of its most valuable customers or users (Chan and Li, 2010; Woisetschläger et al., 2008). Technology companies have been early adopters of online brand communities (DiMauro, 2014) and therefore represent a good choice for a research context.

Moreover, the leading firm-hosted social media brand community - Facebook - is chosen as the focus for studying consumer engagement as this platform engages billions of users on a daily basis. While Facebook might not be seen as a typical FHOBC, it hosts many brand related online communities and brand pages set up by different companies. It has become a powerful research tool as it allows easy access to large and diverse samples. The accessibility in combination with these other strengths makes it an appropriate choice. The focus on two distinct FHOBCs distinguishes this study from other recent studies that have tested the newly developed OCE scale; these studies give participants the opportunity to choose any Facebook-based online brand community (Islam et al, 2017a; Islam et al., 2017b).

\section{Measurement scales}

The measurement scales used in this study have been adapted from past studies. The personality traits scale was adapted from Licata et al. (2003) and the measurement scales for personal values from Lindeman and Verkasalo (2005). The measurement items for OCE were adapted from Hollebeek et al.'s (2014) study and, based on the exploratory interviews discussed above, two items were added to the cognitive and behavioural dimensions of OCE respectively, and one item was added to the emotional dimension. Social value was measured using LeroiWerelds et al.'s (2014) scales. The scale for aesthetic value was adapted from Leroi-Werelds et al. (2014). 
In order to refine and adapt the existing scales to the OCE context, seventeen exploratory interviews were conducted (Netemeyer et al., 2003). The participants were individuals capable of understanding the nature of the concepts that are being investigated (i.e. academics and doctoral researchers in the field of marketing and management). The members of online brand communities (who were the actual unit of analysis) participated in the interviews as well. Interviews lasted between 35 and 45 minutes and were stopped when data saturation was reached (Bertaux, 1981; Morse, 1995). Participants were asked how they saw the constructs of personality traits, personal values, online consumer engagement and perceived value to be related. As a result of these interviews, constructs were revised in order to have a clearer understanding of the construct definitions and statements (see Appendix for measurements).

\section{Research design}

The survey was conducted using an online web survey tool (SurveyMonkey). Given the need to ensure that participants were representative of the FHOBC users, a purposive sampling approach was adopted. Links to the survey were posted on each online community together with a prominent announcement that informed each forum user about the research project and its purpose. Permission from community owners was granted for posting each announcement. In order to account for non-response bias, the demographic profile of respondents was compared to the overall profile of consumers and found to be similar, in terms of age, gender and educational attainment. The unit of analysis for this study is the individual member of at least one of the selected FHOBCs. This choice of an individual user as the unit of analysis is in line with research that claims that the individual is the most frequent unit of analysis in social studies (Corbetta, 2003). The only criterion for participating in this research project is membership of at least one of the FHOBCs selected.

With regard to the sampling frame, it comprises firm-hosted online brand communities. Online brand communities can be divided into firm-hosted online brand communities and non-firmhosted online brand communities. The latter are set up by the customer or user instead of the firm (Ouwersloot and Odekerken-Schröder, 2008). Both communities chosen for this study are ones that have been set up by the firms and sustained by the engagement of the users. The next section deals with the development of the survey instrument for this study.

\section{Survey}

In total, 391 surveys were collected from the social media brand community, whereas 296 surveys have been collected from the FHOBC for customer service support. In total, 687 online 
questionnaire responses have been collected. Following a thorough data cleaning process, a total of 559 questionnaires were retained, which were deemed reliable for further data analysis (Hair and Black, 2013). The demographic profile of the sample indicates a wide spread of age groups and educational backgrounds. The distribution of age of participants is as follows: $34 \%$ are less than 30 years old; $24 \%$ are in the 30-39 age group; $16 \%$ are in the 40-49 age group; $17 \%$ are in the 50-59 age group; $9 \%$ in the 60+ age group. A total of $4 \%$ of the research population indicates their highest qualification to be lower than secondary school; $14 \%$ had completed their GCSEs; 9\% had completed A-level or equivalent; 1\% held a diploma; and 4\% possessed a foundation degree/higher national diploma. Another $19 \%$ had completed an undergraduate degree; $31 \%$ had completed a postgraduate degree; $8 \%$ had completed an MBA; and 7\% had completed a PhD (Doctor of Philosophy), MD (Medical Doctor) or DBA (Doctor of Business Administration). In total, $47 \%$ of participants are female and $52 \%$ are male (1\% prefer not to reveal their gender identity).

\section{Results}

A covariance-based structural equation modelling (SEM) estimation method using the AMOS 22 software was used to examine the measurement and structural components of the model (Jöreskog and Wold, 1982). While the partial least squares (PLS) estimation method could have been an option, PLS is primarily used for predictive analysis and is most suitable for data that has small sample sizes and skewed variables (Haenlein and Kaplan, 2004; Hair et al., 2018. Confirmatory factor analysis (CFA) was run to assess the validity and reliability of the measures. Then, the structural models were estimated to examine validity of the research model and test the research hypotheses ${ }^{1}$.

\section{Reliability and validity of measures}

The measurement model was validated with a confirmatory factor analysis using AMOS 22.0. Reliability of the scales was assessed with Cronbach's alpha $(\alpha)$ and composite reliability (CR) (Hair and Black, 2013). A measure has good reliability if the $\alpha$ and CR scores are above 0.70 (Hair and Black, 2013). Convergent validity is confirmed when the factor loading of each item is high and statistically significant (Malhotra et al., 2017). Thus, factor loadings should be at least 0.50 or higher (Hair and Black, 2013). Moreover, the average variance extracted (AVE) score should be 0.50 or higher to achieve adequate convergent validity (Hair and Black, 2013). The personality trait agreeableness was excluded from the study due to a low Cronbach's alpha,

\footnotetext{
${ }^{1}$ Before examining the measurement and structural models, the normality of the distribution was checked through skewness and kurtosis. The results indicated that the absolute value of the skewness and kurtosis scores were less than 1 and therefore the distributions were normal (Hair et al., 2018)
} 
CR score and not presenting convergent validity. Neuroticism and conscientiousness were excluded, as they did not present convergent validity. Discriminant validity is achieved if the AVE is greater than 0.50 and greater than the squared inter-construct correlations (SIC) for every measure (Fornell and Larcker, 1981). Table 1 shows the scales that reached acceptable reliability and validity.

\section{[Insert TABLE 1 here]}

Reliability and discriminant validity were achieved for all constructs with the exception of altruism as its AVE score was below 0.50. However, altruism is still included because its AVE score is higher than the squared inter correlations (SIC) and its composite reliability is above 0.70 (Fornell and Larcker, 1981). Moreover, convergent validity was achieved for all constructs as all the standardised path coefficients were high and statistically significant. The CFA model excluding the moderator resulted in the following fit indices: $\mathrm{X}^{2}{ }_{(335)}=833.05$; GFI $=0.90$; NFI $=0.92 ; \mathrm{CFI}=0.95 ; \mathrm{RMSEA}=0.05 ; \mathrm{SRMR}=0.05$, which indicate a good fit. The CFA for the model including the moderator resulted in the following fit indices: $\mathrm{X}_{(499)}=1257.24$; $\mathrm{GFI}=$ 0.88; NFI $=0.90 ; \mathrm{CFI}=0.94 ; \mathrm{RMSEA}=0.05 ; \mathrm{SRMR}=0.06$. Although the GFI is below 0.90, the value is still acceptable if the GFI is above 0.80 (Baumgartner and Homburg, 1996; Doll et al., 1994), thus the results still indicate good measurement model validity.

In line with previous research (Lindell and Whitney, 2001; Podaskoff et al., 2003) the following tests have been used to assess common method bias: 1) Harman's single-factor test and 2) the marker variable test. In the Harman's single-factor test common method bias poses a threat if one single unrotated factor appears when conducting exploratory factor analysis in SPSS or if the majority of the variance (more than 50\%) is accounted for by one general factor (Podaskoff et al., 2003). The unrotated factor solution revealed five factors with Eigen values greater than 1. The result accounts for $67.82 \%$ of the total variance, the first factor accounts for $41.37 \%$ of the total variance. Furthermore, with regard to the marker variable test, all adjusted correlations between the marker variable and the items are below the 0.30 threshold, which indicates that common method bias is not an issue for the study (Bagozzi and Yi, 1991; Lages and Piercy, 2012; Lindell and Whitney, 2001).

\section{Testing of the research hypotheses}

After evaluating the measurement model, a structural model was estimated in order to investigate the antecedents and consequences of OCE. The full mediation model was first 
tested. The full mediation model has a good fit $\left(\mathrm{X}^{2}{ }_{(342)}=879.99 ; \mathrm{GFI}=0.90 ; \mathrm{NFI}=0.92 ; \mathrm{CFI}\right.$ $=0.95 ;$ RMSEA $=0.05$ and SRMR $=0.06$ ) as shown in Table 2.

[Insert Table 2 here]

Following Hair and Black (2013), an alternative partial mediation model was tested against the initially proposed full mediation model in order to make sure that the proposed model represents the best way to explain these relationships. The goodness of fit measures for the partial mediation model indicate a good model fit: $\mathrm{X}_{(336)}^{2}=845.19$; GFI $=0.90$; NFI $=0.92$; CFI $=$ 0.95; RMSEA $=0.05$ and SRMR $=0.05$ (see Table 2). An $\mathrm{X}^{2}$ difference test was conducted to compare the full and partial mediation models and the result shows that the partial mediation model provides a better fit for the data collected $\left(\Delta \mathrm{X}^{2}{ }_{(6)}=34.8 ; \mathrm{p}<0.01\right)$ (Brown et al., 2002). The SRMR value is slightly better for the partial mediation model (SRMR $=0.05$ ). Therefore, the partial mediation model was selected for hypotheses testing (Hair and Black, 2013). Hypotheses H1 (extraversion), H4 (openness to experiences) and H6 (altruism) posit positive relationships with OCE (see Table 2). Additional direct relationships have been tested and results show that OCE is positively related to social value and aesthetic value, respectively. In addition, the direct relationship between extraversion and social value is supported and negative in nature and openness to experiences is related to aesthetic value. Hierarchical regression tests were conducted to show the importance of the mediation of OCE. The mediation of OCE explains a greater proportion of variance in social value and aesthetic value than the direct effects of the personality traits variables on their own. The improvement in $\mathrm{R}^{2}$ when OCE was included was statistically significant (Social value: $\Delta \mathrm{R}^{2}=0.25, \Delta \mathrm{F}_{1,554}=242.7, \mathrm{p}<0.01$; Aesthetic value: $\left.\Delta \mathrm{R}^{2}=0.15, \Delta \mathrm{F}_{1,554}=157.93, \mathrm{p}<0.01\right)$. Hence, the inclusion of OCE as a mediator is highly relevant for the study.

Testing the moderation effect of personal values on the relationship between personality traits and $O C E$

In order to test the moderation effect, the self-enhancement measure was split into low and high self-enhancement groups based on the median score. Similarly, the conservation score was split into low and high conservation groups. Table 3 summarises the overall model fit for different groups. 
[Insert Table 3 here]

Results show a better model fit for the model with high self-enhancement than for the model with low self-enhancement. The GFI and NFI values for the model with high self-enhancement are just below the 0.90 threshold but still acceptable within the more liberal 0.80 cut-off point (Garson, 1998). The GFI and NFI values for the model with low self-enhancement are just below the 0.80 threshold but the other fit indices of the model are all within the threshold for good model fit (see Bryne 2010). The model fit for low conservation is slightly better than the model fit for high conservation. Table 4 summarises the results of the moderation model analysis for self-enhancement (H7a, H7d, H7f) and conservation (H8a, H8d, H8f).

\section{[Insert Table 4 here]}

Hypotheses $7 \mathrm{a}, 7 \mathrm{~d}$ and $7 \mathrm{f}$ propose that self-enhancement moderates the relationship between the independent variables and OCE. Self-enhancement strengthens the relationship between extraversion and OCE and between openness to experiences and OCE. Self-enhancement weakens the relationship between altruism and OCE.

Results suggest that the model with low conservation is better in explaining the variance of OCE. One can observe a gap of $31 \%$ between the two models in explaining this variance. In total, $60 \%$ of the variance in online consumer engagement can be explained by the low conservation group in contrast to $29 \%$ by the high conservation group. Hypotheses $8 \mathrm{a}, 8 \mathrm{~d}$ and $8 \mathrm{f}$ propose that conservation moderates the relationship between the independent variables and OCE. The moderator conservation weakens the relationship between all three personality traits (extraversion, openness to experiences, altruism) and OCE. The model for self-enhancement was better in explaining the variance in online consumer engagement. In total, $62 \%$ of the variance in online consumer engagement can be explained by the high self-enhancement group while only $19 \%$ is explained by the low self-enhancement group.

\section{Post-hoc analysis}

In order to check whether there are any differences in terms of the results for the model testing and research hypothesis, we conducted a multi-group analysis for gender (male vs. female). The analysis supported the validity of the model across the two gender groups but differences occurred in terms of the relationship between two of the personality traits, namely extraversion and altruism, and OCE behaviour. The relationship between extraversion and OCE was 
statistically significant for the female group $(\mathrm{SPC}=0.21$, C.R. $=2.88, \mathrm{p}<0.01$ ), which corroborates the overall results, but was insignificant for the male group $(\mathrm{SPC}=0.12, \mathrm{C} . \mathrm{R} .=$ 1.18, $\mathrm{p}>0.05)$. Additionally, the relationship between altruism and OCE was statistically significant for the male group $(\mathrm{SPC}=0.36, \mathrm{C} . \mathrm{R} .=3.82, \mathrm{p}<0.001)$, which corroborates the overall results, but this was not the case for the female group $(\mathrm{SPC}=-0.01, \mathrm{C} . \mathrm{R} .=-0.17, \mathrm{p}>$ 0.05). These findings suggest that extrovert females are more likely to engage with FHOBCs than males. Furthermore, altruistic males are more likely to engage with FHOBCs than females.

The data were collected in two distinct FHOBCs (Model fit: $\chi^{2}(336)=698.74=$; GFI $=0.86$; $\mathrm{NFI}=0.89 ; \mathrm{CFI}=0.94 ; \mathrm{RMSEA}=0.06$ and $\mathrm{SRMR}=0.06$ for firm-hosted social media brand community, Facebook; Model fit: $\chi^{2}{ }_{(336)}=615.15$; GFI $=0.85 ; \mathrm{NFI}=0.88 ; \mathrm{CFI}=$ 0.94; RMSEA $=0.06$ and SRMR $=0.06$ for FHOBC for customer service support). Results indicate that both models have an acceptable fit. The relationship between extraversion and OCE is found to be not significant for the FHOBC for customer service support $(\mathrm{SPC}=0.10$, C.R. $=1.02, p>0.05)$, whereas it is highly significant for the firm-hosted social media brand community Facebook $(\mathrm{SPC}=0.28, \mathrm{C} . \mathrm{R} .=3.63, p<0.001)$. The relationship between altruism and OCE is highly significant for the FHOBC for customer service support (SPC = 0.37, C.R. $=3.57, p<0.0010)$ but not significant for Facebook $(\mathrm{SPC}=0.04$, C.R. $=0.74, p>$ 0.05). The relationship between openness to experiences and OCE is highly significant for Facebook $(\mathrm{SPC}=0.58, \mathrm{C} . \mathrm{R} .=5.58, p<0.001)$ but not for the FHOBC for customer service support $(\mathrm{SPC}=0.21, \mathrm{C} . \mathrm{R} .=1.62, p>0.05)$.

\section{Discussion}

The study suggests that three personality traits - extraversion, openness to experiences and altruism - are key antecedents of OCE. The two personal values, conservation and selfenhancement, moderate the relationship between these three personality traits and OCE. In terms of the consequences of OCE, OCE is positively related to social value and also positively related to aesthetic value. While testing a partial mediation model, two direct relationships were identified, with extraversion being negatively related to social value, and openness to experiences being positively related to aesthetic value. The results of this study address the call for research into personality's relationship with OCE by Wirtz et al. (2013) and McAlexander et al. (2002). The study findings show that individuals who are more extravert have greater engagement with online brand communities as they are more sociable and outgoing. They are also more likely to approach or get to know individuals who have similar interests. The findings also suggest that individuals who are more open to experiences have greater engagement in 
FHOBCs, because it is a manifestation of novelty seeking behaviour. Furthermore, the relationship between altruism and OCE is supported as individuals engaging in an FHOBC like to share their experiences and help others to solve their problems.

Hollebeek (2011), Sung et al. (2010) and Wirtz et al. (2013) highlight the absence of crosscultural research within the OCE literature. The idea that personal values moderate the relationship between personality traits and OCE is appealing as values are concepts that guide behaviour (Homer and Kahle, 1988; Roccas et al., 2002; Schwartz and Bilsky, 1987). This study supports the argument that personal values, namely conservation and self-enhancement, moderate the relationships between personality traits and online engagement. An open-minded individual will engage more online if they are not restricted by the predisposition to follow certain rules embedded in traditions or religious beliefs. Thus, if the individual is low on conservation values (i.e. on tradition, conformity and security) this will facilitate greater levels of online engagement, as they will not be restrained by traditions, customs or rules which might deter contributions to online communities. Such individuals are not held back from taking part in online communities by these social norms as they are open to new experiences, new ideas and interactions with new and different types of people. Conversely, individuals scoring highly on conservation like to restrict themselves, as they are rule-governed, following regulations that they have either set for themselves or that been imposed by others.

Self-enhancement moderates the relationship between extraversion and OCE. If extraverts also score highly on self-enhancement, they are motivated to enhance their personal goals, which then increases online engagement. This occurs because individuals high on self-enhancement are more selfish or self-focussed, and online engagement provides them with an avenue to seek the attention they desire while simultaneously showcasing their achievements. Additionally, the relationship between openness to experiences and OCE was found to be moderated by selfenhancement. Individuals who are more open to experiences engage more in online communities as their curiosity, ambition for success and social power stimulates their online engagement. This enables them to show their expertise or share their experiences and successes, thereby increasing personal prestige. Self-enhancement also moderates the relationship between altruism and online consumer engagement. Individuals who are altruistic in nature are helpful to others and this can provide a strong reason to engage in online communities, as these provide a forum where they can show support for others.

Results reveal that OCE is related to two perceived value types, namely social value and 
aesthetic value, confirming $\mathrm{H} 9$ and H10. This finding is aligned with previous literature suggesting that OCE is related to value creation in general (Higgins and Scholer, 2009; Jaakkola and Alexander, 2014; Kumar et al., 2010) and perceived value in particular (Hollebeek, 2013; Vivek et al., 2012). OCE is positively related to social value which is linked to status and esteem (Holbrook, 1999). Hence, any form of recognition, such as a specific status awarded in the community or an appreciation for something they have achieved, is important for those individuals. Social value can also occur if an individual shapes the responses of others in an FHOBC. Additionally, OCE and aesthetic value are positively related. Aesthetic value occurs when aesthetic aspects of the FHOBC, namely an attractive design (font, easy-to-use layout or appropriate colours) or overall appearance of the FHOBC website, lead to value creation. Moreover, findings show support for two of the six direct relationships between personality traits and perceived value types. In particular, the relationships between extraversion and social value as well as between altruism and aesthetic value are supported. Interestingly, the relationship between extraversion and social value is negative in nature and the direction of the relationship changes when OCE is added as a mediator. A possible explanation for this is that users of FHOBCs who are extraverts by nature might not care about social approval as they have self-confidence. However, if these users engage and interact online by expressing their

opinion and sharing their experiences, they may expect some recognition. Hence, social approval becomes more relevant for them.

Findings of this study show that the OCE scale developed by Hollebeek et al., (2014) may be unidimensional depending on the context of the study (Brodie et al., 2011). Validity of this scale has been supported in the social media context (Islam et al. 2017a) where participants had to be members of at least one Facebook-based online brand community. Moreover, the construct validity of the scale was supported across different contexts (Leckie et al., 2016), and not for specific FHOBCs. Further support for the scale has also been found in the context of people visiting FHOBCs to share travel experiences (Nguyen et al. 2016). Thus, we argue that OCE may be context dependent and therefore unidimensional for the broader context of an FHOBC with the criterion of an actual membership to a specific FHOBC.

\section{Theoretical implications}

This study contributes to OCE theory by bringing together literature from a wide range of disciplines into a conceptual framework focussed on antecedents and consequences of OCE. The study shows empirical support for some of the hypothesised relationships between personality traits (extraversion, openness to experiences and altruism) and OCE, as well as 
between OCE and perceived values (social value, aesthetic value) and the moderating role of personal values (conservation, self-enhancement) on the relationship between personality traits and OCE. The study supports research questioning whether personality traits should be assessed by only the Big Five factors (Brown et al., 2002). Also, results of this study support the integration of additional traits into the Big Five, as only two out of the five personality traits passed reliability and validity tests. Furthermore, the study empirically tests the moderating role of personal values on the relationship between personality traits and OCE.

The findings of the study also suggest that the OCE scale is unidimensional despite including cognitive, emotional and behavioural aspects. As a result, the study contributes to the academic debate on the dimensionality of OCE. Additionally, the present study is the first to apply the short version of Schwartz's personal value scale as a moderator. Finally, this research introduces a perceived value measure that can be used in the context of FHOBC services.

\section{Practical implications}

The results of this study point towards a number of insights for managers seeking to better engage current and future customers in online communities. The study highlights the challenges faced by firms seeking to establish successful online communities. While the technical barriers to creating online communities have never been lower, creating consumer engagement within firm-hosted or firm-managed online communities is much harder. More specifically, given the breadth of different platforms and online communities competing for customers' attention and time, this study points to a number of proactive steps that managers can take to improve levels of engagement in online communities.

By understanding the influence of different personality traits on online consumer engagement, managers are able to focus on activities that will strengthen online communities. For example, this study highlights the role of altruistic individuals in answering questions and helping others with problem solving, suggesting that this group might be best engaged by providing them with some formal recognition (e.g. contributors' star rankings) that enables and motivates them to engage within a community. To leverage this altruism the first step to improve engagement in FHOBCs is for its employees to understand that their role is to facilitate discussion and not act as 'content creators'. For example, community managers should facilitate answers instead of simply replying to questions. Secondly, if community managers can get to know their brand advocates well, they can be aware of who has the knowledge to reply to a specific question and 
can guide customers to those who can help address their questions most effectively by tagging them in the message.

Another step is to leverage the role of extraverts in recruiting and engaging new community members. For example, managers could assess levels of extraversion through analysis of posting frequency and offer incentives to customers that remain engaged in the community. Findings of this study also highlight that personal values moderate the relationship between personality traits and online consumer engagement. Even though community managers may not be able to influence personal values, they should be aware of how they influence online behaviour so that they are able to deal with the potential consequences.

Findings also indicate that a community must be collaborative in order to meet consumer expectations for social value when engaging online. Social approval can be shown by the online brand community, the brand, its employees or other users in any form. Thus, it is essential for online community managers to encourage and reward consumers' engagement whether through awarding forms of online status (e.g. points, badges or labels that provide recognition), invitations to contribute content to a website (e.g. writing an article) or inviting advocates to key team meetings in order to share their expertise and feel they are involved in the company's decision making. For the most active brand advocates promotion opportunities could be offered including interviews or awards that provide public recognition. Even for less active members, regularly receiving regular thanks from community managers can help building social value. These awards can be of symbolic as well as financial value. For example, while support can be acknowledged with branded company items (e.g. t-shirt or mug), a digital plaque or certificate is a cost-free option that can be used to express thanks to a user who has made a certain number of valuable or helpful posts.

Users of both FHOBCs in this study perceived both aesthetic value and social value as a result of online consumer engagement. This highlights again the importance of holistic approaches to considering overall user experience, including good website design, overall appearance and responsive layouts across a range of devices to create more effective information searches. Community managers should have clear onboarding processes and strategies to reach out to new community members and to introduce both themselves and the purpose of the community. By explaining how to get started, how to navigate and how to complete a profile, the brand community will be able to more quickly demonstrate value to new members. Other suggestions 
in relation to aesthetic value are that the FHOBC manager should ensure that the content and dialogue is kept honest and easy to follow so that the FHOBC shows only important insights. This aim can be achieved by monitoring the quality of customer comments, seeking to avoid repetition and ensuring that online discussion remains friendly, avoiding the forms of hostile social interactions that can often be seen in unmoderated social media contexts.

\section{Limitations and future research directions}

In presenting this research, we acknowledge some limitations as well as a number of future research directions. Despite the specificity of the context in this study, both the theoretical contribution and fast-changing nature of online communities provide promising avenues for further research. The first limitation is the use of self-reported measures. Despite the potential for social desirability bias where respondents may present themselves in a favourable light (Furnham, 1986), self-reported measures are a commonly used method in research on personality traits (e.g. Coelho et al., 2016). A second limitation relates to the potential for findings to be culturally bound, due to online communities with an individual national focus being selected, where cultural values might impact upon the behaviour of individuals (Hofstede and McCrae, 2004). Hence, future research is recommended to apply this study's conceptual framework across different cultures to enhance its generalisability. Future research could also consider additional types of consumer perceived value such as economic value and altruistic value and their role in other OCE contexts.

In order to develop a deeper understanding of the concept of consumer engagement, future research could also consider broader theoretical and practical implications, such as developing and testing theoretical frameworks of the psychological process of engagement (Calder et al., 2016) or relating engagement to happiness (Calder et al., 2016). Future research could also look at how and why personal values influence engagement. Additionally, reflecting broader shifts in the nature and use of online communities, and thus the interaction between brands and consumers in these communities, a valuable focus for future research lies in developing a richer understanding of engagement across a range of social and technological contexts. For example, research on online engagement across cultures, in business-to-business (B2B) settings (Hollebeek et al., 2016a), interdisciplinary research (Calder et al., 2016), the investigation of focal engagement stakeholder group roles, activities, practices and responsibilities (e.g. Pervan and Bove, 2011; Schau et al., 2009) and the interface between engagement and big data (Hollebeek et al., 2016a) constitute directions for further research. 


\section{References}

Ajzen, I. (2005), Attitudes, Personality and Behaviour (Vol. 2), Open University Press, Maidenhead.

Algesheimer, R., Dholakia, U.M. and Hermann, A. (2005), "The social influence of brand community: Evidence from European car clubs", Journal of Marketing, Vol. 69 No. 1, pp. 19-34. doi: http://dx.doi.org/10.1509/jmkg.69.3.19.66363

Amichai-Hamburger, Y. and Ben-Artzi, E. (2000), "The relationship between extraversion and neuroticism and the different uses of the internet", Computers in Human Behavior, Vol. 16 No. 4, pp. 441-449. doi: 10.1016/S0747-5632(00)00017-0

Amichai-Hamburger, Y. and Ben-Artzi, E. (2003), "Loneliness and internet use", Computers in Human Behavior, Vol. 19 No. 1, pp. 71-80. doi: http://dx.doi.org/10.1016/S07475632(02)00014-6

Amichai-Hamburger, Y. and Vinitzky, G. (2010), "Social network use and personality", Computers in Human Behavior, Vol. 26 No. 6, pp. 1289-1295. doi: 10.1016/j.chb.2010.03.018

Bagozzi, R.P. and Yi, Y. (1991), "Multitrait-multimethod matrices in consumer research", Journal of Consumer Research, Vol. 17 No. 1, pp. 426-439. doi: http://www.jstor.org/stable/2626837

Baumgartner, H. and Homburg, C. (1996), "Applications of structural equation modeling in marketing and consumer research: A review", International Journal of Research in Marketing, Vol. 13 No. (2), pp. 139-161. doi: 10.1016/0167-8116(95)00038-0

Bejerholm, U. and Eklund, M. (2007), "Occupational engagement in persons with schizophrenia: Relationships to self-related variables, psychopathology and quality of life", The American Journal of Occupational Therapy, Vol. 61 No. 1, pp. 21-32. doi: 10.5014/ajot.61.1.21

Bertaux, D. (1981), "From the life-history approach to the transformation of sociological practice", in Biography and Society: The Life History Approaches in the Social Sciences, Sage Publications Ltd, Beverley Hills, pp. 29-45.

Block, J. (1995), "A contrarian view of the five-factor approach to personality description", Psychological Bulletin, Vol. 117 No. 2, pp. 187-215. doi: http://dx.doi.org/10.1037/0033-2909.117.2.187

Bolton, R. N. (2011), "Customer engagement: Opportunities and challenges for organisations", Journal of Service Research, Vol. 14 No. 3, pp.272-274. doi:10.1177/1094670511414582

Borle, S. and Singh, S. (2008), "Customer lifetime value measurement", Management Science, Vol. 54 No. 1, pp. 100-112. doi: http://dx.doi.org/10.1287/mnsc.1070.0746

Brodie, R.J., Hollebeek, L., Juric, B. and Ilic, A. (2011), "Customer engagement: Conceptual domain, fundamental propositions, and implications for research", Journal of Service Research, Vol. 14, No. 3, pp. 252-271. doi: 10.1177/1094670511411703

Brodie, R.J., Ilic, A., Juric, B. and Hollebeek, L. (2013), "Consumer engagement in a virtual brand community: An exploratory analysis", Journal of Business Research, Vol. 66 No. 1, pp. 105-114. doi: http://dx.doi.org/10.1016/j.jbusres.2011.07.029

Brown, T.J., Mowen, J.C., Donavan, T. and Licata, J. (2002), "The customer orientation of service workers: Personality trait effects on self- and supervisor performance ratings", Journal of Marketing Research, Vol. 39 No. 1, pp. 110-119. doi: http://dx.doi.org/10.1509/jmkr.39.1.110.18928

Bryne, B.M. (2010), Structural Equation Modeling with AMOS: Basic Concepts, Applications and Programming, Routledge, New York.

Butt, S. and Phillips, J.G. (2008), "Personality and self reported mobile phone use", Computers in Human Behavior, Vol. 24 No. 2, pp. 346-360. doi: http://dx.doi.org/10.1016/j.chb.2007.01.019 
Calder, B.J., Malthouse, E.C. and Maslowska, E. (2016), "Brand marketing, big data and social innovation as future research directions for engagement", Journal of Marketing Management, Vol. 32 Nos. 5-6, pp. 579-585. doi: http://dx.doi.org/10.1080/0267257X.2016.1144326

Cattell, R.B. (1947), "Confirmation and clarification of primary personality factors", Psychometrika, Vol. 12 No. 3, pp. 197-220. doi: 10.1007/BF02289253

Chan, K.W. and Li, S.Y. (2010), "Understanding consumer-to-consumer interactions in virtual communities: The salience of reciprocity", Journal of Business Research, Vol. 63 No. 9-10, pp. 1033-1040. doi: http://dx.doi.org/10.1016/j.jbusres.2008.08.009

Chen, T. (2011), "Personality traits hierarchy of online shoppers", International Journal of Marketing Studies, Vol. 3 No. 4, pp. 23-39. doi: http://dx.doi.org/10.5539/ijms.v3n4p23

Chow, C.W., Yijtaka Kato, C.W. and Shields, M.D. (1994), "National culture and the preference for management controls: An exploratory study of the firm-labor market interface", Accounting, Organizations and Society, Vol. 19 No. 4, pp. 381-400. doi: http://dx.doi.org/10.1016/0361-3682(94)90003-5

Coelho, F., Lages, C.R. and Sousa, C. (2016), "Personality and the creativity of frontline service employees: Linear and curvilinear effects", The International Journal of Human Resource Management, pp. 1-28. doi: http://dx.doi.org/10.1080/09585192.2016.1255982

Corbetta, P. (2003), Social Research: Theory, Methods and Techniques, Sage Publications, London.

Correa, T., Willard, A.W. and Zúniga, H.G. (2010), "Who interacts on the web? The intersection of users' personality and social media use", Computers in Human Behavior, Vol. 26 No. 1, pp. 247-253. doi: 10.1016/j.chb.2009.09.003

Costa, P.T. and McCrae, R.R. (1992a), "Four ways five factors are basic", Personality and Individual Differences, Vol. 13 No. 6, pp. 653-665. doi: http://dx.doi.org/10.1016/0191-8869(92)90236-I

Costa, P.T. and McCrae, R.R. (1992b), "Normal personality assessment in clinical practice: The NEO personality inventory”, Psychological Assessment, Vol. 4 No. 1, pp. 5-13. doi: http://dx.doi.org/10.1037/1040-3590.4.1.5

Digman, J.M. (1990), "Personality structure: Emergence of the five-factor model", Annual Review of Psychology, Vol. 41 No. 1, pp. 417-440. doi: 10.1146/annurev.ps.41.020190.002221

Digman, J.M. and Takemoto-Chock, N.K. (1981), "Factors in the natural language of personality: Re-analysis, comparison, and interpretation of six major studies", Multivariate Behavioral Research, Vol. 16 No. 2, pp. 149-170. doi: http://dx.doi.org/10.1207/s15327906mbr1602_2

DiMauro, V. (2014), "71 top online customer communities: The big list", available at: http://www.leadernetworks.com/2011/02/71-top-online-customer-communitiesbig.html (accessed 11 September 2017).

Dlugokinski, E. and Firestone, I.J. (1973), "Congruence among four methods of measuring other-centeredness", Child Development, Vol. 44 No. 2, pp. 304-308. doi: $10.2307 / 1128051$

Dodds, W.B., Monroe, K.B. and Grewal, D. (1991), "Effects of price, brand, and store information on buyers' product evaluations", Journal of Marketing Research, Vol. 28 No 3, pp. 307-319. doi: http://www.jstor.org/stable/3172866

Doll, W.J., Xia, W. and Torkzadeh, G. (1994), "A confirmatory factor analysis of the enduser computing satisfaction instrument”, MIS Quarterly, Vol. 18 No. 4, pp. 357-369. doi: $10.2307 / 249524$ 
Evans, J. (1941), “A new measure of introversion - extroversion”, The Journal of Psychology: Interdisciplinary and Applied, Vol. 12 No. 1, pp. 111-124. doi: 10.1080/00223980.1941.9917060

Evans, J. and Mavondo, F.T. (2002), "Psychic distance and organisational performance: An empirical examination of international retailing operations", Journal of International Business Studies, Vol. 33 No. 3, pp. 515-532. doi: 10.1057/palgrave.jibs.8491029

Evans, J., Treadgold, A. and Mavondo, F. (2000), "Explaining export development through psychic distance", International Marketing Review, Vol. 17 No. 2, pp. 164-168. doi: http://dx.doi.org/10.1108/02651330010322688

Eysenck, H.J. (1991), "Dimensions of personality: 16, 5 or 3? - Criteria for a taxonomic paradigm", Personality and Individual Differences, Vol. 12 No. 8, pp. 773-790. doi: 10.1016/0191-8869(91)90144-Z

Feist, J. and Feist, G.J. (2008), Theories of Personality (Vol. 7), McGraw-Hill Higher Education, New York.

Fiske, D. W. (1949), "Consistency of the factorial structures of personality ratings from different sources”,The Journal of Abnormal and Social Psychology, Vol. 44 No. 3, pp.329-344. doi:http://dx.doi.org/10.1037/h0057198

Fornell, C. and Larcker, D.F. (1981), "Evaluating structural equation models with unobservable variables and measurement error", Journal of Marketing Research, Vol. 18 No. 1, pp. 39-50. doi: 10.2307/3151312

Fournier, S. and Lee, L. (2009), "Getting brand communities right", Harvard Business Review, Vol. 87 No. 4, pp. 105-113.

Furnham, A. (1986), "Response bias, social desirability and dissimulation", Personality and Individual Differences, Vol. 7 No. 3, pp. 385-400. doi: 10.1016/0191-8869(86)900140

Garson, D. (1998), Neural Networks: An Introductory Guide for Social Scientists, Sage Publications, London.

Goldberg, L.R. (1990). "An alternative "description of personality": The Big-Five factor structure", Journal of Personality and Social Psychology, Vol. 59 No. 6, pp. 12161229. doi: http://dx.doi.org/10.1037/0022-3514.59.6.1216

Gosling, S.D. and Augustine, A.A. (2011), "Facebook-related behaviours and observable profile information”, CyberPsychology, Behavior and Social Networking, Vol. 14 No. 9, pp. 483-488. doi: 10.1089/cyber.2010.0087

Haenlein, M. and Kaplan, A.M. (2004), "A beginner's guide to partial least squares analysis", Understanding Statistics, Vol. 3 No. 4, pp. 283-297. doi:

10.1207/s15328031us0304_4

Hair, J.F. and Black, W.C. (2013), Multivariate Data Analysis, Prentice Hall, New Jersey.

Hair, J.F., Black, W.C., Babin, B.J. and Anderson, R.E. (2018), Multivariate Data Analysis, Prentice Hall, New Jersey.

Harris, E.G., Mowen, J.C. and Brown, T.J. (2005), "Re-examining salesperson goal orientations: Personal influencers, customer orientation, and work satisfaction", Journal of the Academy of Marketing Science, Vol. 33 No. 1, pp. 19-35. doi: $10.1177 / 0092070304267927$

Harris, E.G. and Lee, J.M. (2004), "Illustrating a hierarchical approach for selecting personality traits in personnel decisions: An application of the 3M model", Journal of Business and Psychology, Vol. 19 No. 1, pp. 53-67. doi: 10.1023/B:JOBU.0000040272.84608.83

Harwood, T. and Garry, T. (2010), “'It's mine!' - Participation and ownership within virtual co-creation environments", Journal of Marketing Management, Vol. 26 Nos. 3-4, pp. 290-301. doi: http://dx.doi.org/10.1080/02672570903566292 
Higgins, E.T. and Scholer, A.A. (2009), "Engaging the consumer: The science and art of the value creation process, Journal of Consumer Psychology, Vol. 19 No. 2, pp. 100-114. doi: $10.1016 /$ j.jcps.2009.02.002

Hofstede, G. (1984), Culture's Consequences: International Differences in Work-Related Values, SAGE Publications Ltd, London.

Hofstede, G. and McCrae, R.R. (2004), "Personality and culture revisited: Linking traits and dimensions of culture, Cross-cultural Research, Vol. 38 No. 1, pp. 52-88. doi: $10.1177 / 1069397103259443$

Holbrook, M. (1999), Consumer Value: A Framework for Analysis and Research, Routledge, Oxon.

Holbrook, M. (2006), “Consumption experience, customer value, and subjective personal introspection: An illustrative photographic essay, Journal of Business Research, Vol. 59 No. 6, pp. 714-725. doi: http://dx.doi.org/10.1016/j.jbusres.2006.01.008

Hollebeek, L. (2011), "Demystifying customer brand engagement: Exploring the loyalty nexus", Journal of Marketing Management, Vol. 27 Nos. 7-8, pp. 785-807. doi: http://dx.doi.org/10.1080/0267257X.2010.500132

Hollebeek, L. (2013), “The customer engagement/value interface: An exploratory investigation", Australasian Marketing Journal, Vol. 21 No. 1, pp. 17-23. doi: http://dx.doi.org/10.1016/j.ausmj.2012.08.006

Hollebeek, L. and Chen, T. (2014), "Exploring positively-versus negatively valenced brand engagement: A conceptual model", Journal of Product and Brand Management, Vol. 23 No. 1, pp. 62-74. doi: http://dx.doi.org/10.1108/JPBM-06-2013-0332

Hollebeek, L., Conduit, J., Sweeney, J., Soutar, G.N., Karpen, I.O., Jarvis, W. and Chen, T. (2016a), "Epilogue to the special issue and reflections on the future of engagement research", Journal of Marketing Management, Vol. 32 Nos. 5-6, pp. 586-594. doi: http://dx.doi.org/10.1080/0267257X.2016.1144340

Hollebeek, L. Glynn, M.S. and Brodie, R.J. (2014), "Consumer brand engagement in social media: Conceptualization, scale development and validation", Journal of Interactive Marketing, Vol. 28 No. 2, pp. 149-165. doi: 10.1016/j.intmar.2013.12.002

Homer, P. and Kahle, L.R. (1988), "A structural equation test of the value attitude behavior hierarchy”, Journal of Personality and Social Psychology, Vol. 54 No. 1. doi: http://dx.doi.org/10.1037/0022-3514.54.4.638

Huo, Y.J., Binning, K.R. and Molina, L.E. (2009), "Testing an integrative model of respect: Implications for social engagement and well-being", Personality and Social Psychology Bulletin, Vol. 20 No. 10, pp. 1-13. doi: 10.1177/0146167209356787

Islam, J., Rahman, Z. and Hollebeek, L. (2017a), "Personality factors as predictors of online consumer engagement: An empirical investigation", Marketing Intelligence and Planning, Vol. 35 No. 4, pp. 510-528. doi: https://doi.org/10.1108/MIP-10-2016-0193

Islam, J., Rahman, Z. and Hollebeek, L. (2017b), "Consumer engagement in online brand communites: A solicitation of conguity theory", Internet Research, in press.

Jaakkola, E. and Alexander, M. (2014), "The role of customer engagement behavior in value co-creation: A service system perspective", Journal of Service Research, Vol. 17 No. 3, pp. 247-261. doi: 10.1177/1094670514529187

Jöreskog, K.G. and Wold, H. (1982), "The ML and PLS techniques for modeling with latent variables: Historical and comparative aspects", Systems Under Indirect Observation: Causality, Structure, Prediction, Part 1, New Holland, Amsterdam.

Kim, J.W. and Gray, S.J. (2009), "An assessment of alternative empirical measures of cultural distance: Evidence from the Republic of Korea", Asia Pacific Journal of Management, Vol. 26 No. 1, pp. 55-74. doi: 10.1007/s10490-007-9061-4

Kumar, V., Aksoy, L., Donkers, B., Venkatesan, R., Wiesel, T. and Tillmanns, S. (2010), "Undervalued or overvalued customers: Capturing total customer engagement value", 
Journal of Service Research, Vol. 13 No. 3, pp. 297-310. doi:

10.1177/1094670510375602

Kumar, V., Rajkumar, V., Bohling, T. and Beckmann, D. (2008), "Practice price report-The power of CLV: Managing customer lifetime value at IBM", Management Science, Vol. 27 No. 4, pp. 585-599. doi: http://dx.doi.org/10.1287/mksc.1070.0319

Lages, C.R. and Piercy, N.F. (2012), "Key drivers of frontline employee generation of ideas for customer service improvement", Journal of Service Research, Vol. 15 No. 2, pp. 215-230. doi: 10.1177/1094670511436005

Leary, M.R. and Allen, A. (2011), "Self-presentational persona: Simultaneous management of multiple impressions", Journal of Personality and Social Psychology, Vol. 101 No. 1, pp. 1033-1049. doi: http://dx.doi.org/10.1037/a0023884

Leckie, C., Nyadzayo, M. W., \& Johnson, L. W. (2016), “Antecedents of consumer brand engagement and brand loyalty", Journal of Marketing Management, Vol. 32 No. 5-6, pp. 558-578. doi:http://dx.doi.org/10.1080/0267257X.2015.1131735

Lee, E., Ahnb, J. and Kim, Y. J. (2014), "Personality traits and self-presentation at Facebook", Personality and Individual Differences, Vol. 69 No. 1, pp. 162-167. doi: 10.1016/j.paid.2014.05.020

Leroi-Werelds, S., Streukens, S., Brady, M.K. and Swinnen, G. (2014), “Assessing the value of commonly used methods for measuring customer value: A multi-setting empirical study", Journal of the Academy of Marketing Science, Vol. 42 No. 4, pp. 430-451. doi: 10.1007/s11747-013-0363-4

Licata, J.W., Mowen, J.C., Harris, E.G. and Brown, T.J. (2003), "A hierarchical personality approach for identifying the traits of high-performing service personnel", Journal of the Academy of Marketing Science, Vol. 31 No. 3, pp. 256-271. doi: 10.1177/0092070303031003004

Lindell, M.K. and Whitney, D.J. (2001), "Accounting for common method variance in crosssectional research designs", Journal of Applied Psychology, Vol. 86 No. 1, pp. 114121. doi: 10.1037//0021-9010.86.1.114

Lindeman, M. and Verkasalo, M. (2005), "Measuring values with the short Schwartz's value survey", Journal of Personality Assessment, Vol. 85 No. 2, pp. 170-178. doi: http://dx.doi.org/10.1207/s15327752jpa8502_09

Madjar, N. (2008), "Emotional and informational support from different sources and employee creativity", Journal of Occupational and Organizational Psychology, Vol. 81 No. 1, pp. 83-100. doi: 10.1348/096317907X202464

Malhotra, N.K., Birks, D. and Nunan, D. (2017), Marketing Research: An Applied Orientation (5th ed.), Pearson Education, London.

Malone, G.P., Pillow, D.R. and Osman, A. (2012), "The general belongingness scale (GBS): Assessing achieved belongingness", Personality and Individual Differences, Vol. 52 No. 3, pp. 311-316. doi: http://dx.doi.org/10.1016/j.paid.2011.10.027

Marbach, J., Lages, C.R. and Nunan, D. (2016), "Who are you and what do you value? Investigating the role of personality traits and customer-perceived value in online customer engagement", Journal of Marketing Management, Vol. 32 Nos. 5-6. doi: http://dx.doi.org/10.1080/0267257X.2015.1128472

Marks, H.M. (2000), "Student engagement in instructional activity: Patterns in the elementary, middle and high school years", American Educational Research Journal, Vol. 37 No. 1, pp. 153-184. doi: 10.3102/00028312037001153

Marshall, T.C., Lefringhausen, K. and Ferenczi, N. (2015), "The Big Five, self-esteem and narcissism as predictors of the topics people write about in Facebook status updates", Personality and Individual Differences, Vol. 85 No. 1, pp. 35-40. doi: 10.1016/j.paid.2015.04.039 
Maslowska, E., Malthouse, E.C. and Collinger, T. (2016), "The customer engagement ecosystem”, Journal of Marketing Management, Vol. 32 Nos. 5-6, pp. 469-501. doi: http://dx.doi.org/10.1080/0267257X.2015.1134628

Matthews, G., Deary, I.J. and Whiteman, M.C. (2009). Personality Traits (Vol. 3), Cambridge University Press, Cambridge.

McAlexander, J.H., Schouten, J.W. and Koenig, H.F. (2002), "Building brand community", Journal of Marketing, Vol. 66 No. 1, pp. 38-54. doi: http://dx.doi.org/10.1509/jmkg.66.1.38.18451

McCrae, R.R. and Costa, P.T. (1987), "Validation of the five-factor model of personality across instruments and observers", Journal of Personality and Social Psychology, Vol. 52 No. 1, pp. 81-90. doi: http://dx.doi.org/10.1037/0022-3514.52.1.81

McCrae, R.R. and Costa, P.T. (1991), "Adding liebe und arbeit: The full five factor model and well being”, Personality and Social Psychology Bulletin, Vol. 17 No. 2, pp. 227232. doi: http://dx.doi.org/10.1177/014616729101700217

McCrae, R.R. and John, O.P. (1992), "An introduction to the five-factor model and its applications", Journal of Personality, Vol. 60 No. 2, pp. 175-215. doi: 10.1111/j.14676494.1992.tb00970.x

McElroy, J.C., Hendrickson, A.R., Townsend, A.M. and DeMarie, S.M. (2007), "Dispositional factors in internet use: Personality versus cognitive style", MIS Quarterly, Vol. 31 No. 1, pp. 809-820. doi: http://www.jstor.org/stable/25148821

McSweeney, B. (2002), "Hofstede's model of national cultural differences and their consequences: A triumph of faith - a failure of analysis", Human Relations, Vol. 55 No. 1, pp. 89-118. doi: http://hum.sagepub.com/cgi/content/abstract/55/1/89

Misra, R., Mukherjee, A. and Peterson, R.T. (2008), "Value creation in virtual communities: The case of a healthcare web site", International Journal of Pharmaceutical and Healthcare Marketing, Vol. 2 No. 4, pp. 321-337. doi: http://dx.doi.org/10.1108/17506120810922358

Monroe, K.B. (1979), Pricing: Making Profitable Decisions, McGraw-Hill, New York.

Mottram, A.J. and Fleming, M.J. (2009), "Extraversion, impulsivity and online group membership as predictors of problematic internet use", CyberPsychology and Behavior, Vol. 12 No. 3, pp. 319-321. doi: 10.1089/cpb.2007.0170

Mowen, J. C. (2000), "The 3M Model of motivation and personality: Theory and empirical applications to consumer behaviour", Kluwer Academic Publishers, Norwell.

Mowen, J.C. and Spears, N. (1999), "Understanding compulsive buying among college students: A hierarchical approach”, Journal of Consumer Psychology, Vol. 8 No. 4, pp. 407-430. doi: http://dx.doi.org/10.1207/s15327663jcp0804_03

Mowen, J.C. and Sujan, H. (2005), "Volunteer behavior: A hierarchical model approach for investigating its trait and functional motive antecedents", Journal of Consumer Psychology, Vol. 15 No. 2, pp. 170-182. doi: http://dx.doi.org/10.1207/s15327663jcp1502_9

Muñiz, A.M.J. and O'Guinn, T.C. (2001), "Brand community", Journal of Consumer Research, Vol. 27 No. 4, pp. 412-432. doi: 10.1086/319618

Mustak, M. (2014), "Value for business customers: Conceptualisation, process, and evaluation", paper presented at the 13th International Research Conference in Service Management, La Londe les Maures, France.

Netemeyer, R.G., Bearden, W.O. and Sharma, S. (2003), Scaling Procedures: Issues and Applications, Sage O'Reilly, London.

Ng, S.I., Lee, J.A. and Soutar, G.N. (2007), “Are Hofstede's and Schwartz's value frameworks congruent?”, International Marketing Review, Vol. 24 No. 2, pp. 164180. doi: http://dx.doi.org/10.1108/02651330710741802 
Nguyen, L.T.V., Conduit, J., Lu, V.N. and Hill, S.R. (2016), "Engagement in online communities: Implications for consumer price perceptions", Journal of Strategic Marketing, Vol. 24 Nos. 3-4, pp. 241-260. doi: http://dx.doi.org/10.1080/0965254X.2015.1095224

Norman, W.T. (1963), "Toward an adequate taxonomy of personality attributes: Replicated factor structure in peer nomination personality ratings", The Journal of Abnormal and Social Psychology, Vol. 66 No. 6, pp. 574-583. doi: http://dx.doi.org/10.1037/h0040291

Ouwersloot, H. and Odekerken-Schröder, G. (2008), "Who's who in brand communities and why?", European Journal of Marketing, Vol. 42 Nos. 5/6, pp. 571-585. doi: http://dx.doi.org/10.1108/03090560810862516

Pervan, S. and Bove, L. (2011), "The engagement of customers beyond their expected roles", Journal of Strategic Marketing, Vol. 19 No. 7, pp. 30-51. doi: http://dx.doi.org/10.1080/0965254X.2011.599498

Podaskoff, P.M., MacKenzie, S.B., Lee, J.Y. and Podaskoff, N.P. (2003), "Common method bias in behavioural research: A critical review of the literature and recommended redemies", Journal of Applied Psychology, Vol. 88 No. 5, pp. 879-903. doi: 10.1037/0021-9010.88.5.879

Porter, C.E., Devaraj, S. and Sun, D. (2013), “A test of two models of value creation in virtual communities", Journal of Management Information Systems, Vol. 30 No. 1, pp. 261292.

Raja, U. and John, G. (2010), "The joint effects of personality and job scope on in-role performance", Human Relations, Vol. 63 No. 7, pp. 981-1005. doi: $10.1177 / 0018726709349863$

Roccas, S., Sagiv, L., Schwartz, S.H. and Knafo, A. (2002), "The big five personality factors and personal values", Personality and Social Psychology Bulletin, Vol. 28 No. 6, pp. 789-801. doi: http://dx.doi.org/10.1177/0146167202289008

Roccas, S. and Schwartz, S.H. (2010), "Personal value priorities and national identification", Political Psychology, Vol. 31 No. 3, pp. 393-419. doi: 10.1111/j.14679221.2010.00763.x

Rose, S., Clark, M., Samouel, P. and Hair, N. (2012), "Online customer experience in eretailing: An empirical model of antecedents and outcomes", Journal of Retailing, Vol. 88 No. 2, pp. 308-322. doi: 10.1016/j.jretai.2012.03.001

Ross, C., Orr, E.S., Sisic, M., Arseneault, J.M., Simmering, M.G. and Orr, R.R. (2009), "Personality and motivations associated with Facebook use", Human Behaviour, Vol. 25 No. 2, pp. 578-586. doi: http://dx.doi.org/10.1016/j.chb.2008.12.024

Ruiz, D.M., Gremler, D.D., Washburn, D.A. and Carrión, G.C. (2008), "Service value revisited: Specifying a higher-order, formative measure", Journal of Business Research, Vol. 61 No. 12, pp. 1278-1291. doi: 10.1016/j.jbusres.2008.01.015

Rushton, J.P., Chrisjohn, R.D. and Fekken, G.C. (1981), "The altruistic personality and the self-report altruism scale", Personality and Individual Differences, Vol. 2 No. 4, pp. 293-302. doi: 10.1016/0191-8869(81)90084-2

Rutherford, E. and Mussen, P. (1968), "Generosity in nursery school boys", Child Development, Vol. 39 No. 3, pp. 755-765. doi: http://www.jstor.org/stable/1126981

Ryan, T. and Xenos, S. (2011), "Who uses Facebook? An investigation into the relationship between the Big Five, shyness, narcissism, loneliness, and Facebook usage", Computers in Human Behavior, Vol. 27 No. 5, pp. 1658-1664. doi: http://dx.doi.org/10.1016/j.chb.2011.02.004

Schau, H.J., Muñiz, A.M.J. and Arnould, E.J. (2009), "How brand community practices create value", Journal of Marketing, Vol. 73 No. 5, pp. 30-51. doi:

http://dx.doi.org/10.1509/jmkg.73.5.30 
Schnell, T. and Becker, P. (2006), "Personality and meaning in life", Personality and Individual Differences, Vol. 41 No. 1, pp. 117-129. doi: http://dx.doi.org/10.1016/j.paid.2005.11.030

Schwartz, S.H. (1992), "Universals in the content structure of values: Theoretical advances and empirical tests in 20 countries", Advances in Experimental Social Psychology, Vol. 25 No. 1, pp. 19-45. doi: http://dx.doi.org/10.1016/S0065-2601(08)60281-6

Schwartz, S.H. (1999), "A theory of cultural values and some implications for work", Applied Psychology, Vol. 48 No. 1, pp. 23-47. doi: 10.1111/j.1464-0597.1999.tb00047.x

Schwartz, S. H., and Bilsky, W. (1987). Toward a universal psychological structure of human values. Journal of Personaliy and Social Psychology, 53(1), 550-562. doi:http://dx.doi.org/10.1037/0022-3514.53.3.550

Seidman, G. (2013), "Self-presentation and belonging on Facebook: How personality influences social media use and motivations", Personality and Individual Differences, Vol. 54 No. 3, pp. 402-407. doi: 10.1016/j.paid.2012.10.009

Seraj, M. (2012), "We create, we connect, we respect, therefore we are: Intellectual, social and cultural value in online communities", Journal of Interactive Marketing, Vol. 26 No. 4, pp. 209-222. doi: http://dx.doi.org/10.1016/j.intmar.2012.03.002

Soares, A. M., Farhangmehr, M., \& Shoham, A. (2007), "Hofstede's dimensions of culture in international marketing studies", Journal of Business Research, Vol. 60 No. 1, pp. 277-284. doi:http://dx.doi.org/10.1016/j.jbusres.2006.10.018

Sousa, C.M.P., Coelho, F. and Lages, C.R. (2016), "Personality and the creativity of frontline service employees: Exploring quadratic and moderating effects", in Campbell, C and Ma, J.J. (Eds.), Looking Forward, Looking Back: Drawing on the Past to Shape the Future of Marketing, Springer International Publishing, pp. 407.

Steenkamp, J.B.E.M. (2001), "The role of national culture in international marketing research", International Marketing Review, Vol. 18 No. 1, pp. 30-44. doi: http://dx.doi.org/10.1108/02651330110381970

Suls, J., Green, P. and Hillis, S. (1998), "Emotional reactivity to everyday problems, affective inertia, and neuroticism", Personality and Social Psychology Bulletin, Vol. 24 No. 2, pp. 127-136. doi: http://dx.doi.org/10.1177/0146167298242002

Sung, Y., Kim, Y., Kwon, O. and Moon, J. (2010), “An explorative study of Korean consumer participation in virtual brand communities in social network sites", Journal of Global Marketing, Vol. 23 No. 5, pp. 430-445. doi:

http://dx.doi.org/10.1080/08911762.2010.521115

Taggar, S. (2002), "Individual creativity and group ability to utilise individual creative resources; a multilevel model", Academy of Management Journal, Vol. 45 No. 2, pp. 315-330. doi: 10.2307/3069349

Tsao, W.C. (2013), "Big Five personality traits as predictors of internet usage categories", International Journal of Management, Vol. 30 No. 4, pp. 374-386.

Van Doorn, J., Lemon, K.N., Mittal, V., Nass, S., Pick, D., Pirner, P. and Verhoef, P.C. (2010), "Customer engagement behaviour: Theoretical foundations and research directions", Journal of Service Research, Vol. 13 No. 3, pp. 253-266. doi: $10.1177 / 1094670510375599$

Vargo, S.L. and Lusch, R.F. (2008), "Service dominant logic: Continuing the evolution", Journal of the Academy of Marketing Science, Vol. 36 No. 1, pp. 1-10. doi: 10.1007/s11747-007-0069-6

Verhoef, P.C., Reinartz, W.J. and Krafft, M. (2010), "Customer engagement as a new perspective in customer management", Journal of Service Research, Vol. 13 No. 3, pp. 247-252. doi: http://dx.doi.org/10.1177/1094670510375461

Verleye, K., Gemmel, P. and Rangarajan, D. (2013), "Managing engagement behaviors in a network of customers and stakeholders: Evidence from the nursing home sector", 
Journal of Service Research, Vol. 17 No. 1, pp. 68-84. doi:

$10.1177 / 1094670513494015$

Vivek, S.D., Beatty, S.E. and Morgan, R.M. (2012), "Customer engagement exploring customer relationships beyond purchase", The Journal of Marketing Theory and Practice, Vol. 20 No. 2, pp. 122-146. doi: 10.2753/MTP1069-6679200201

Wang, Y., Lo, H.P., Chi, R. and Yang, Y. (2004), “An integrated framework for customer value and customer-relationship-management performance: A customer-based perspective from China", Managing Service Quality, Vol. 14 Nos. 2/3, pp. 169-182. doi: http://dx.doi.org/10.1108/09604520410528590

Wiertz, C. and De Ruyter, K. (2007), "Beyond the call of duty: Why customers contribute to firm-hosted commercial online communities", Organization Studies, Vol. 28 No. 3, pp. 347-376. doi: 10.1177/0170840607076003

Wilson, K., Fornasier, S. and White, K.M. (2010), "Psychological predictors of young adults: Use of social networking sites", CyberPsychology, Behavior and Social Networking, Vol. 13 No. 2, pp. 173-177. doi: 10.1089/cyber.2009.0094

Wirtz, J., Den Ambtman, A., Bloemer, J., Horvath, C., Ramaseshan, B., Van de Kludert, J., . . . Kandamoully, J. (2013), "Managing brands and customer engagement in online brand communities”, Journal of Service Management, Vol. 24 No. 3, pp. 223-244. doi: http://dx.doi.org/10.1108/09564231311326978

Woisetschläger, D.M., Hartleb, V. and Blut, M. (2008), "How to make brand communities work: Antecedents and consequences of consumer participation", Journal of Relationship Marketing, Vol. 7 No. 3, pp. 237-256. doi: http://dx.doi.org/10.1080/15332660802409605

Woodall, T. (2003), “Conceptualising 'value for the customers': An attributional, structural and dispositional analysis", Academy of Marketing Science Review, Vol. 12 No. 1, pp. $1-30$.

Woodruff, R.B. (1997), "Customer value: The next source for competitive advantage", Journal of the Academy of Marketing, Vol. 25 No. 2, pp. 139-153. doi: 10.1007/BF02894350

Zeithaml, V.A. (1988), "Consumer perceptions of price, quality, and value: A means-end model and synthesis of evidence", Journal of Marketing, Vol. 52 No. 3, pp. 2-22. doi: $10.2307 / 1251446$ 
Figure 1: Conceptual framework

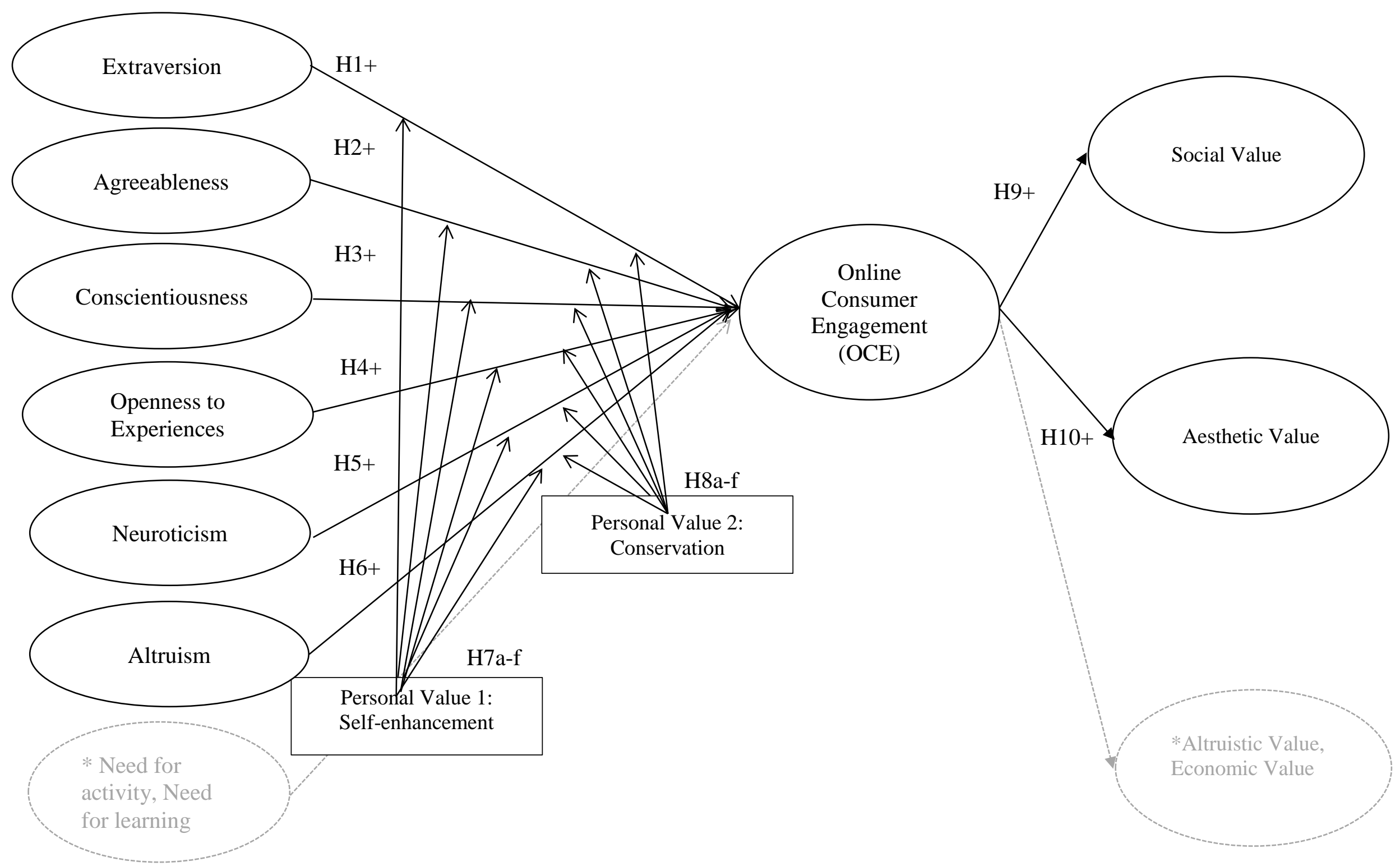

Note: *Other additional personality traits could be need for activity or need for learning (Mowen and Sujan, 2005) and other categories of consumer value could be altruistic value and economic value (Holbrook, 1999), which might arise in other specific contexts. 
Table 1: Measurement model: Descriptive statistics, bivariate correlations and average variance extracted

\begin{tabular}{|c|c|c|c|c|c|c|c|c|c|c|c|c|}
\hline & Mean & SD & $\alpha$ & $\mathrm{CR}$ & 1 & 2 & 3 & 4 & 5 & 6 & 7 & 8 \\
\hline 1. Extraversion & 5.48 & 1.08 & 0.87 & 0.87 & 0.53 & 0.53 & 0.34 & 0.36 & 0.10 & 0.26 & 0.35 & 0.26 \\
\hline 2. Openness to experiences & 5.43 & 0.96 & 0.81 & 0.75 & $0.73 *$ & 0.54 & 0.42 & 0.48 & 0.17 & 0.35 & 0.41 & 0.18 \\
\hline 3. Altruism & 5.21 & 0.94 & 0.78 & 0.79 & $0.58 *$ & $0.65^{*}$ & 0.48 & 0.31 & 0.16 & 0.22 & 0.16 & 0.05 \\
\hline 4. OCE & 4.95 & 1.35 & 0.92 & 0.86 & $0.60^{*}$ & $0.69 *$ & $0.56^{*}$ & 0.62 & 0.49 & 0.49 & 0.31 & 0.14 \\
\hline 5. Social value & 4.50 & 1.65 & 0.90 & 0.91 & $0.31 *$ & $0.41 *$ & $0.40^{*}$ & $0.70 *$ & 0.76 & 0.31 & 0.24 & 0.03 \\
\hline 6. Aesthetic value & 5.40 & 1.25 & 0.93 & 0.93 & $0.51 *$ & $0.59 *$ & $0.47 *$ & $0.70 *$ & $0.56^{*}$ & 0.83 & 0.28 & 0.07 \\
\hline 7. Self-enhancement & 5.37 & 1.22 & 0.79 & 0.81 & $0.59 *$ & $0.64 *$ & $0.40 *$ & $0.56^{*}$ & $0.49 *$ & $0.53 *$ & 0.59 & 0.05 \\
\hline 8. Conservation & 4.28 & 1.30 & 0.82 & 0.83 & $-0.51 *$ & $-0.42 *$ & $-0.23 *$ & $-0.37 *$ & $-0.16^{* *}$ & $-0.27^{*}$ & $-0.23^{*}$ & 0.62 \\
\hline
\end{tabular}

Note: SD = Standard Deviation; $\alpha=$ Cronbach's Alpha; CR = Composite Reliability; AVE = Average Variance Extracted Values are diagonal in bold; (IC) Inter-Construct

Correlations are in the lower diagonal; SIC $=$ Squared Inter-Construct Correlations are in the upper diagonal; $*=p<0.001 ; * *=p<0.01$ 
Table 2: Results of the structural equation model: The full and partial mediation models

\begin{tabular}{lllll}
\hline Relationships & \multicolumn{2}{l}{ Full Mediation } & \multicolumn{2}{l}{ Partial Mediation } \\
& SPC & CR & SPC & CR \\
\hline $\mathrm{H}_{1}$ Extraversion $\rightarrow$ OCE & 0.17 & $2.79^{* *}$ & 0.17 & $2.91^{* *}$ \\
$\mathrm{H}_{4}$ Openness $\rightarrow$ OCE & 0.46 & $6.33^{* * *}$ & 0.46 & $6.25^{* * *}$ \\
$\mathrm{H}_{6}$ Altruism $\rightarrow$ OCE & 0.17 & $3.11^{* *}$ & 0.16 & $2.94^{* *}$ \\
$\mathrm{H}_{9}$ OCE $\rightarrow$ Social value & 0.70 & $12.26^{* * *}$ & 0.80 & $10.79^{* * *}$ \\
$\mathrm{H}_{10}$ OCE $\rightarrow$ Aesthetic value & 0.71 & $13.02^{* * *}$ & 0.56 & $9.19^{* * *}$ \\
Extraversion $\rightarrow$ Social value & & & -0.17 & $-2.84^{* *}$ \\
Extraversion $\rightarrow$ Aesthetic value & & & 0.03 & 0.60 \\
Openness $\rightarrow$ Social value & & & -0.08 & $2.19^{* *}$ \\
Openness $\rightarrow$ Aesthetic value & & & 0.15 & -1.10 \\
Altruism $\rightarrow$ Social value & & & 0.11 & 1.84 \\
Altruism $\rightarrow$ Aesthetic value & & & 0.04 & 0.69
\end{tabular}

\section{Model Fit Statistics}

$\chi^{2}$

879.99

845.19

$\mathrm{df}$

342

336

RMSEA

0.05

0.05

SRMR

0.06

0.05

GFI

0.90

0.90

NFI

0.92

0.92

CFI

0.95

0.95

\section{Squared Multiple Correlation $\left(\mathbf{R}^{2}\right)$}

Online consumer engagement
0.52
0.51
0.51
0.52
0.48
0.52

Aesthetic value

Social value

Note: SPC = Standardised Path Coefficient; CR = Critical Ratio; OCE = Online Consumer Engagement; df $=$ Degrees of Freedom; RMSEA = Root Mean Square Error of Approximation; SRMR = Standardised Root Mean Residual; GFI = Goodness of Fit Index; NFI = Normed Fit Index; CFI = Comparative Fit Index; $* * * \mathrm{p}<0.001 ; * * \mathrm{p}<0.01$ 
Table 3: Overall model fit statistics

\begin{tabular}{|c|c|c|c|c|c|c|c|c|}
\hline & $\mathbf{N}$ & $\chi^{2}$ & df & GFI & NFI & CFI & RMSEA & SRMR \\
\hline Model with Low & 559 & 555.94 & 336 & 0.77 & 0.78 & 0.90 & 0.07 & 0.08 \\
\hline \multicolumn{9}{|l|}{ Self-enhancement } \\
\hline Model with High & 559 & 746.54 & 336 & 0.89 & 0.89 & 0.94 & 0.05 & 0.06 \\
\hline \multicolumn{9}{|l|}{ Self-enhancement } \\
\hline Model with Low & 559 & 629.88 & 336 & 0.88 & 0.89 & 0.94 & 0.05 & 0.06 \\
\hline \multicolumn{9}{|l|}{ Conservation } \\
\hline Model with High & 559 & 597.48 & 336 & 0.84 & 0.86 & 0.93 & 0.06 & 0.07 \\
\hline
\end{tabular}

Note: df = Degrees of Freedom; GFI = Goodness of Fit Index; NFI = Normed Fit Index; CFI = Comparative Fit Index; RMSEA = Root Mean Square Error of Approximation; SRMR = Standardised Root Mean Residual

Table 4: Results of the moderation model for conservation and self-enhancement

\begin{tabular}{|c|c|c|c|c|c|c|c|c|}
\hline \multirow[t]{3}{*}{ Relationships } & \multicolumn{4}{|c|}{ Self-enhancement } & \multicolumn{4}{|c|}{ Conservation } \\
\hline & Low & & High & & Low & & High & \\
\hline & SPC & $\mathbf{C R}$ & SPC & $\mathbf{C R}$ & SPC & CR & SPC & $\mathbf{C R}$ \\
\hline $\mathrm{H}_{7 \mathrm{a} ; 8 \mathrm{a}}$ Extraversion $\rightarrow \mathrm{OCE}$ & 0.13 & 1.19 & 0.15 & $2.48 * *$ & 0.08 & 1.02 & 0.16 & 1.82 \\
\hline $\mathrm{H}_{7 \mathrm{~d} ; 8 \mathrm{~d}}$ Openness $\rightarrow$ OCE & -0.14 & -1.16 & 0.70 & $7.29 * * *$ & 0.56 & $5.30 * * *$ & 0.33 & $3.44 * * *$ \\
\hline $\mathrm{H}_{7 f ; ~}^{8 f}$ Altruism $\rightarrow$ OCE & 0.42 & $3.36 * * *$ & -0.03 & -0.51 & 0.20 & $2.52 * *$ & 0.16 & 1.86 \\
\hline
\end{tabular}

Note: SPC = Standardised Path Coefficient; CR = Critical Ratio; OCE = Online Consumer Engagement; $* * * \mathrm{p}<0.001 ; * * \mathrm{p}<0.01$ 


\section{Extraversion*}

\section{Consumer Personality}

1. I feel uncomfortable in a group of people. (R)

0.76

0.83

0.68

0.76

0.64

0.69

6. I am withdrawn. (R)

Openness to Experiences

1. I frequently feel highly creative.

3. I am innovative.

0.86

0.73

5. I enjoy beauty more than others.

Altruism

1. I am altruistic.

3. I sacrifice my goals to help others.

4. I am selfless in giving time to others.

\section{Personal Values}

\section{Self-enhancement}

1. The importance of POWER -

that is social power, authority and wealth.

2. The importance of HEDONISM -

that is gratification of desires, enjoyment in life and self-indulgence.

3. The importance of ACHIEVEMENT -

that is success, capability, ambition and influence on people and events.

\section{Conservation}

1. The importance of TRADITION -

that is respect for tradition, humbleness,

accepting one's position in life, devotion and modesty.

2. The importance of CONFORMITY -

that is obedience, honouring parents and elders, self-discipline and politeness.

3. The importance of SECURITY -

that is national security, family security, social order, cleanliness

and return of favours.

Online Consumer Engagement (OCE)

1. I think about Facebook a lot when I'm using it.

of their services.*

3. I feel very positive when I use Facebook.

4. Using Facebook makes me happy. $\quad 0.89$

5. I'm proud to use Facebook. 0.86

6. I spend a lot of time using Facebook compared $\quad 0.59$

to other social networking pages.

7. I use Facebook to learn about other users' experiences.**

\section{Perceived Value}

\section{Social Value}

Facebook

1. ...helps me feel accepted.

2 ....improves the way I am perceived.

Thinking about Facebook.

1. The layout of the page is attractive. $\quad 0.92$

0.92

2 . The design of the page is visually appealing.

0.87 